\title{
Erratum to: The impact of user fees on health services utilization and infectious disease diagnoses in Neno District, Malawi: a longitudinal, quasi-experimental study
}

S. I. Watson ${ }^{1+}$, E. B. Wroe ${ }^{2,3^{*}+}$, E. L. Dunbar ${ }^{2}$, J. Mukherjee ${ }^{4}$, S. B. Squire ${ }^{5}$, L. Nazimera ${ }^{6}$, L. Dullie ${ }^{2+}$ and R. J. Lilford ${ }^{1+}$

\section{Erratum}

Upon publication of this article [1], it was brought to our attention that Fig. 1 was incorrectly presented. The correct Fig. 1 is shown below:

\begin{abstract}
Author details
${ }^{1}$ University of Warwick, Coventry, UK. ${ }^{2}$ Partners In Health/Abwenzi Pa Za Umoyo, PO Box 56, Neno, Malawi. ${ }^{3}$ Brigham \& Women's Hospital, Boston, USA. ${ }^{4}$ Partners In Health, Boston, MA, USA. ${ }^{5}$ Liverpool School of Tropical Medicine, Liverpool, UK. ${ }^{6}$ Ministry of Health, Neno District, Malawi.
\end{abstract}

Received: 1 November 2016 Accepted: 1 November 2016

Published online: 04 November 2016

\section{Reference}

1. Watson SI, et al. The impact of user fees on health services utilization and infectious disease diagnoses in Neno District, Malawi: a longitudinal, quasiexperimental study. BMC Health Serv Res. 2016;16:595. doi:10.1186/s12913016-1856-x.

\footnotetext{
* Correspondence: ewroe@pih.org

${ }^{\dagger}$ Equal contributors

${ }^{2}$ Partners In Health/Abwenzi Pa Za Umoyo, PO Box 56, Neno, Malawi

3Brigham \& Women's Hospital, Boston, USA
} 


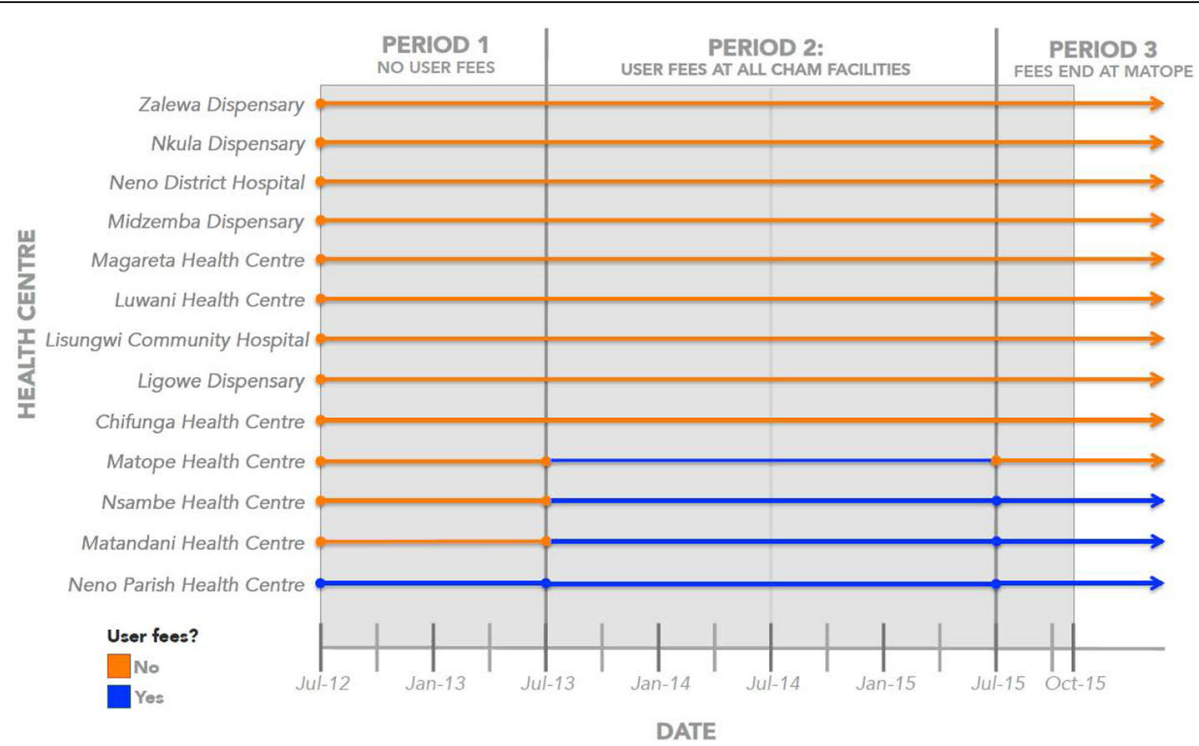

Fig. 1 Implementation of user fees across health centres in Neno District, Malawi 